\title{
Nghiên cứu đánh giá khả năng xử lý nước thải giết mổ bằng bể phản ứng sinh học giá thể cố định
}

\section{Evaluating the use of biofilter as a pre-treatment step for slaughterhouse wastewater treatment}

\author{
Mai Thị Thùy Trang ${ }^{1}$, Phạm Ngọc Danh ${ }^{1}$, Trần Thái Hà ${ }^{*}$ \\ ${ }^{1}$ Trường Đại học Mở Thành phố Hồ Chí Minh, Việt Nam \\ *Tác giả liên hệ, Email: ha.tt@ou.edu.vn
}

THÔNG TIN

DOI: $10.46223 /$ HCMCOUJS. tech.vi.14.1.441.2019

Ngày nhận: 18/04/2019

Ngày nhận lại: 10/07/2019

Duyệt đăng: 17/09/2019

Tù̀ khóa:

bể phản ứng sinh học, hiệu quả xử lý, màng sinh học, nước thải giết mổ, vật liệu giá thể cố định

Keywords:

biofilm, biofilter, fixed bed material, treatment capacity, slaughterhouse wastewater

\section{TÓM TĂT}

Nghiên cứu được thực hiện nhằm đánh giá khả năng xử lý nước thải giết mổ heo từ một cơ sở tại tỉnh Bến Tre bằng bể phản ứng sinh học giá thể cố định (Biofilter). Nghiên cứu được thực hiện bằng việc xây dựng mô hình bể biofilter, kèm theo quan sát việc hình thành màng sinh học trên giá thể. Hiệu quả xử lý nước thải được đánh giá thông qua bốn chỉ tiêu ô nhiễm gồm: TSS, $\mathrm{BOD}, \mathrm{N}-\mathrm{NH}^{+}$, độ đục. Hiệu quả thu được tốt nhất qua nghiên cứu là: $\operatorname{TSS} 78,93 \%, \mathrm{BOD} 88,77 \%, \mathrm{~N}^{-N^{+}}{ }_{4} 87,50 \%$ và độ đục $96,61 \%$. Tuy nhiên nồng độ BOD, TSS, Amoni sau bể phản ứng vẫn cao hơn giá trị cho phép xả thải quy định trong QCVN 40 2011/BTNMT nên bể phản ứng sinh học giá thể cố định chỉ nên được áp dụng như là công đoạn tiền xử lý và cần thiết phải có công đoạn xử lý tiếp theo để các chỉ tiêu trên đạt quy chuẩn.

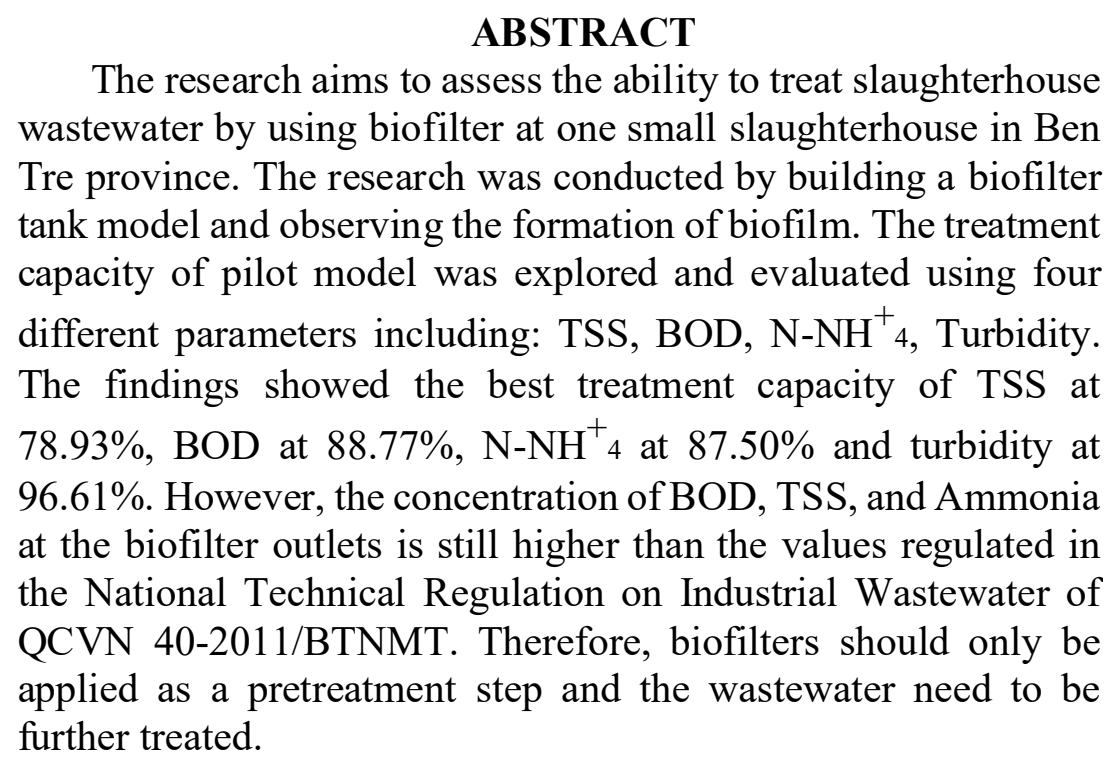




\section{1. Đặt vấn đề}

Trong hoạt động giết mổ, nước được sử dụng hầu hết các công đoạn (giết, cạo lông, mổ, xẻ thịt, vệ sinh, ...) với định mức sử dụng nước khoảng $5-15 \mathrm{~m}^{3} /$ tấn gia súc và lượng nước này toàn bộ chuyển thành nước thải. Nước thải giết mổ gia súc là nguồn nước thải có hàm lượng chất ô nhiễm cao (chất hữu cơ, chất dinh dưỡng, chất rắn lơ lửng), sẽ gây ô nhiễm môi trường nếu không xử lý tốt Choi và Eum (2002), Le, Le, và Nguyen, (2012).

Tính đến năm 2017, Theo cổng thông tin điện tử Bộ Nông nghiệp và Phát triển nông thôn, Bến Tre vẫn chưa hình thành được cơ sở giết mổ vừa và lớn, các cơ sở giết mổ nhỏ lẻ chưa có cơ sở xử lý nước thải hoặc có nhưng vận hành không hiệu quả (Thông tấn xã Việt Nam, 2017). Nước thải được xả trực tiếp ra môi trường sẽ làm ô nhiễm đất, nước và sức khỏe người dân trong khu vực xung quanh. Do đó việc nghiên cứu để tìm ra một công nghệ xử lý nước thải giết mổ là cần thiết.

Nước thải giết mổ được xử lý bằng dây chuyền công nghệ kết hợp quá trình cơ học, hóa-lý, sinh học (Grady, Glen, \& Henry, 1999; Luong, 2007; Metcalf \& Eddy, 2016; V. P. Nguyen, 2010; Trinh, 2009). Trong đó xử lý sinh học được coi là giai đoạn chính để loại bỏ chất hữu cơ, chất dinh dưỡng gây ô nhiễm môi trường. Vì vậy phương pháp sử dụng các giá thể để các vi sinh vật bám dính lên bề mặt vật liệu được lựa chọn vì hệ thống này có nhiều ưu điểm nổi bật như cấu tạo đơn giản, hiệu quả xử lý cao, chi phí cho xây dựng và vận hành thấp...rất thích hợp áp dụng xử lý nước thải giết mổ phù hợp với điều kiện tỉnh Bến Tre.

\section{Vật liệu và phương pháp nghiên cứu}

\subsection{Nội dung nghiên cúu}

\subsection{1. Đối tượng nghiên cưu}

Mẫu nước thải chăn nuôi được lấy tại lò giết mổ heo hộ gia đình Hai Cảnh, huyện Mỏ Cày, tỉnh Bến Tre. Nước thải lấy ở mương từ khu giết mổ thoát ra cống trước khi vào hệ thống Biogas, tại thời điểm từ $9-10$ giờ sáng, ngay sau khi giết mổ heo khoảng $15-30$ phút. Nước thải là hồn hợp bao gồm một phần máu, nước rửa nội tạng, lông... Mỗi lần lấy 40 lít trong 2 bình nhựa 20 lít, đủ số lượng cho cả đợt chạy mô hình thí nghiệm. Mẫu nước thải được bảo quản trong điều kiện lạnh $4^{0} \mathrm{C}$ trong tủ lạnh ở phòng Thí nghiệm Hóa - Môi trường, Trường Đại học Mở thành phố Hồ Chí Minh, Cơ sở 3 Bình Dương. Các thông số ô nhiễm chính của nước thải từ cơ sở Hai Cảnh được trình bày trong Bảng 1 .

\section{Bảng 1}

Thông số nước thải giết mổ của cơ sở hộ gia đình Hai Cảnh

\begin{tabular}{|c|c|c|c|}
\hline STT & Chỉ tiêu & Đơn vi & Giá trị \\
\hline 1 & $\mathrm{BOD}_{5}$ & $\mathrm{mg} / \mathrm{l}$ & 2000 \\
\hline 2 & $\mathrm{COD}$ & $\mathrm{mg} / \mathrm{l}$ & 2600 \\
\hline 3 & $\mathrm{TSS}$ & $\mathrm{mg} / \mathrm{l}$ & 1000 \\
\hline 4 & Amoni $\left(\mathrm{NH}_{4}^{+}\right)$tính theo $\mathrm{N}$ & $\mathrm{mg} / \mathrm{l}$ & 40 \\
\hline 5 & Nitrat $\left(\mathrm{NO}_{3}^{-}\right)$tính theo $\mathrm{N}$ & $\mathrm{mg} / \mathrm{l}$ & 45 \\
\hline 6 & Độ đục & $\mathrm{NTU}$ & 360 \\
\hline
\end{tabular}

Nguồn: Kết quả phân tích dữ liệu của nhóm nghiên cứu 
Qua Bảng 1, tỷ lệ $\mathrm{BOD} / \mathrm{COD}$ hoà $\tan =0,77>0,5 ; \mathrm{COD} / \mathrm{BOD}=1.3<2$. Điều này thể hiện nước thải giết mổ gia súc rất thích hợp cho xử lý sinh học. Trong nghiên cứu này, BOD, TSS ở dòng vào có thay đổi thông số trong từng đợt lấy. $\mathrm{NH}_{4}$ và $\mathrm{NO}_{3}$ giữ ở mức ổn định.

\subsubsection{Nội dung nghiên cúu}

Vật liệu sử dụng trong nghiên cứu này là đất nung viên, có kích thước 10 - 20mm, trọng lượng riêng là $300-400 \mathrm{~kg} / \mathrm{m}^{3}$, trọng lượng nhẹ phù hợp với bể (Hình 1). Bề mặt vật liệu có vô số lổ hổng thích hợp để vi sinh dánh bám và phát triển. Đất nung được sản xuất ở nhiệt độ cao nên sản phẩm sẽ không có những vi sinh không mong muốn khác. Hạt nung giữ ẩm $30 \%$ vừa đủ để ngậm các chất hữu ẩm, cho vi sinh vật sử dụng. Các khoảng cách giữa các hạt vật liệu tạo đủ khoảng không để vi sinh vật lấy ôxi.

Trong giai đoạn đầu của thí nghiệm thì chế phẩm vi sinh EM-Pro được dùng như mồi vi sinh phát triển. Chế phẩm được mua từ SACOTEC, bao gồm các chủng Saccharomyces sp.: 109cfu/ml; Lactobacillus sp.: $10^{9} \mathrm{cfu} / \mathrm{ml}$; Bacillus sp.: $10^{9} \mathrm{cfu} / \mathrm{ml}$; Rhodopseudomonas sp.: $10^{8} \mathrm{cfu} / \mathrm{ml}$; Dung dịch chế phẩm có màu vàng nâu nhạt; $\mathrm{pH} 3.5$; tỉ trọng: 1 ; mùi thơm nhẹ.

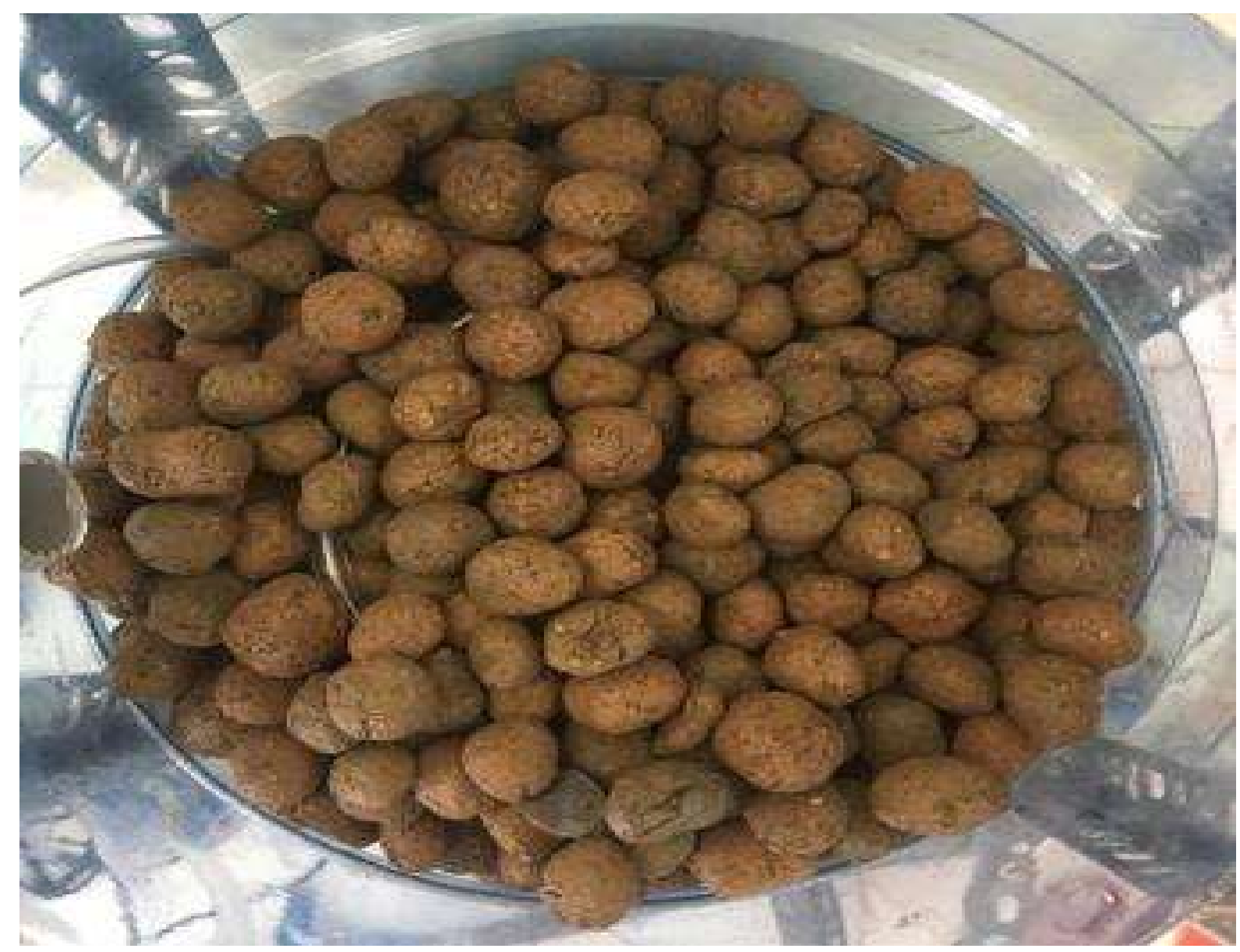

Hình 1. Vật liệu dính bám đất nung 


\subsubsection{Phương pháp phân tích}

\section{Bảng 2}

Các phương pháp phân tích

\begin{tabular}{|c|c|c|c|}
\hline STT & Chỉ tiêu & Đơn vị & Thiết bị \\
\hline 1 & $\mathrm{BOD}_{5}$ & $\mathrm{mg} / \mathrm{l}$ & $\begin{array}{c}\text { Dissolved Oxygen Test kit HI3810 } \\
\text { Tủ ủ } 20^{\circ} \mathrm{C}\end{array}$ \\
\hline 2 & TSS & $\mathrm{mg} / \mathrm{l}$ & $\begin{array}{l}\text { Giấy lọc thủy tinh, bộ hút chân } \\
\text { không, tủ nung và cân phân tích. }\end{array}$ \\
\hline 3 & Amoni & $\mathrm{mg} / \mathrm{l}$ & Amonia Test kit HI 3824 \\
\hline 4 & Độ đục & $\mathrm{mg} / \mathrm{l}$ & $\begin{array}{c}\text { Máy Đo Độ Đục Tiêu Chuẩn ISO } \\
\text { HI93703 }\end{array}$ \\
\hline
\end{tabular}

Nguồn: Kết quả phân tích dữ liệu của nhóm nghiên cứu

Các chỉ tiêu này được phân tích tại Phòng thí nghiệm Hóa - Môi trường, trường Mở Thành phố Hồ Chí Minh, cơ sở 3.

\subsection{Mô hình nghiên cúu}

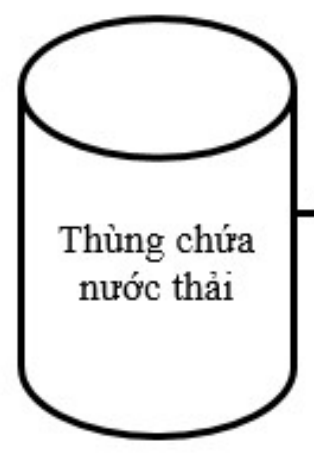

Dòng vàn

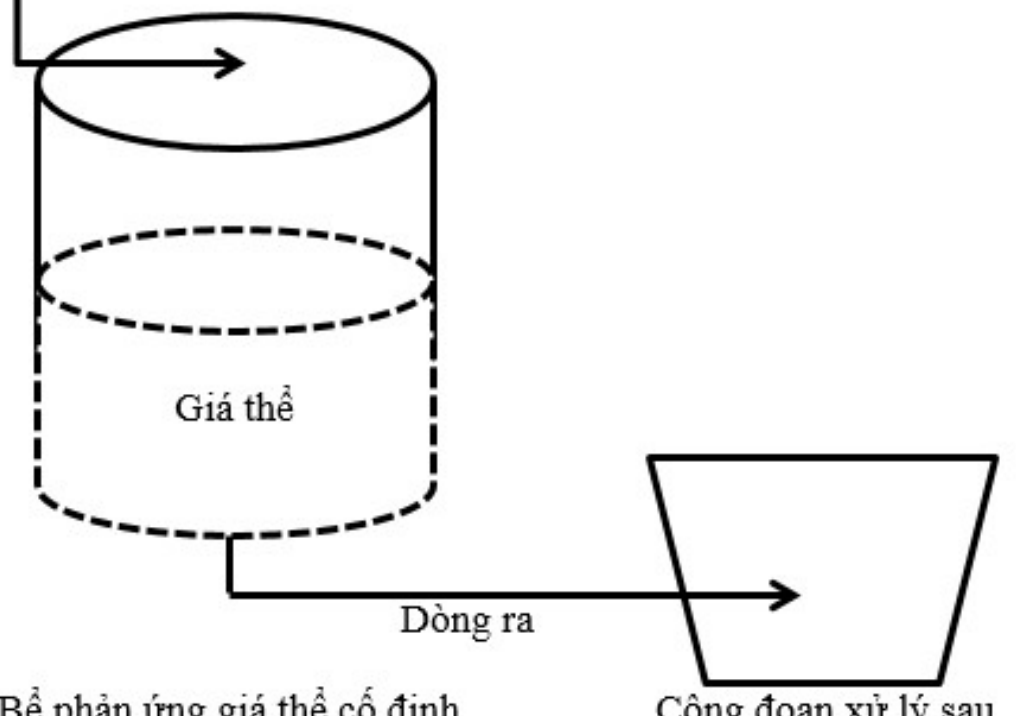

Bể phản ứng giá thể cố định 


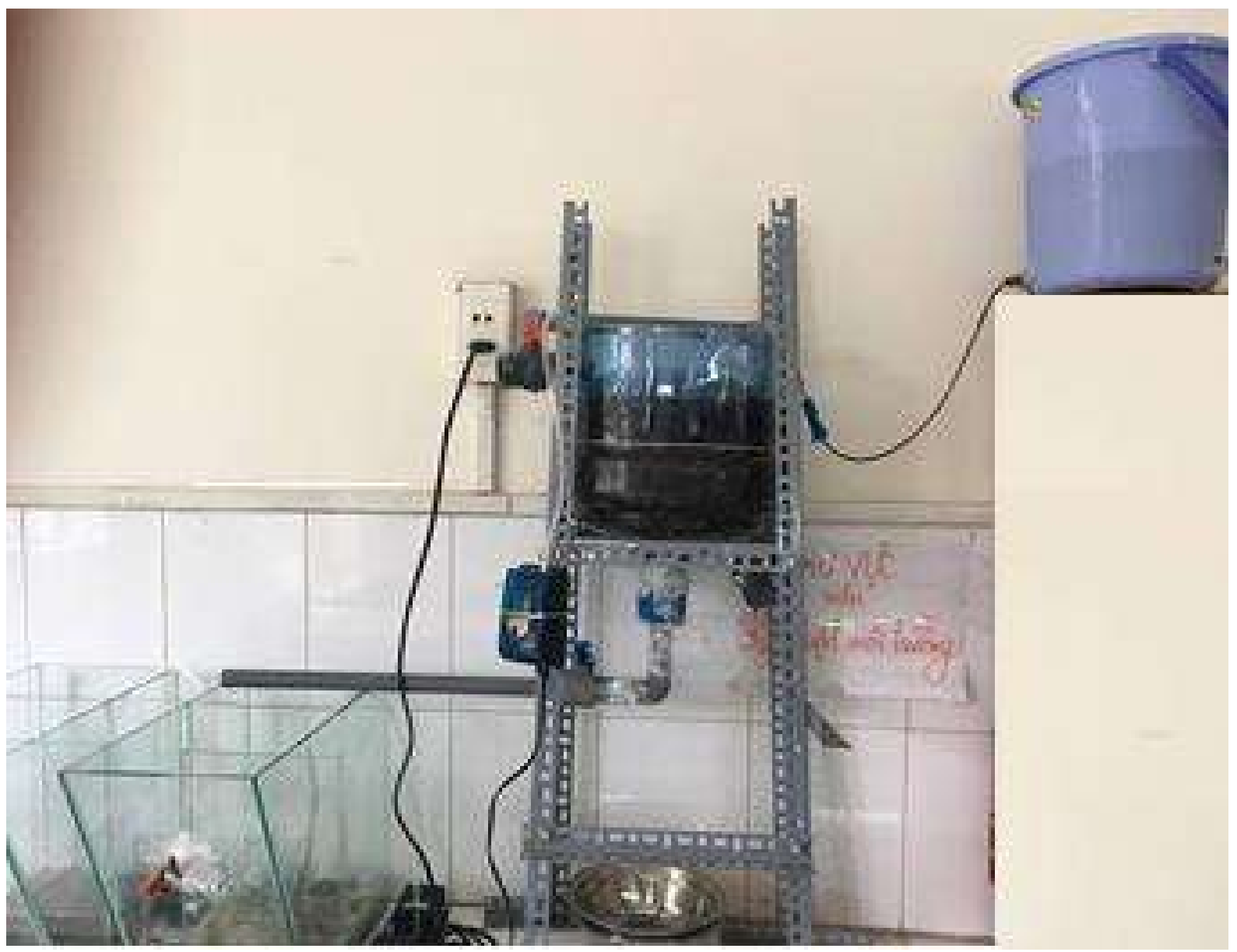

Hình 2. Mô hình nghiên cứu

Cấu tạo của mô hình: Bể phản ứng sinh học giá thể cố định (Biofilter) được làm từ vật liệu là bình nhựa đựng nước $20 \mathrm{~L}$ tái chế cắt bỏ $1 / 3$ phần đầu bình (Hình 1 ), giữ lại phần bình có đường kính $24 \mathrm{~cm}$, chiều cao $20 \mathrm{~cm}$, phần vật liệu chiếm $2 / 3$ bể. Thể tích nước thải có thể chứa trong bể khi đã chứa lớp vật liệu là $5 \mathrm{~L}$. Bên dưới đáy bể có van xả cặn sau khi bể hoạt động lâu ngày và xuất hiện lượng dưới đáy nhiều. Bình đựng nước đầu vào có thể tích $8 \mathrm{~L}$ có gắn ống dẫn nước, có van điều chỉnh lưu lượng. Ống dẫn được nối với ống nhựa được đục lỗ để nước thải được trải đều xuống mặt vật liệu. Ống dẫn nước thải ở đầu ra bể có van khóa và bể có thiết bị sục khí thổi khí liên tục.

Nguyên tắc vận hành mô hình: Mô hình được thiết kế nhằm kết hợp các quá trình xử lý $\mathrm{BOD}$, quá trình nitrate hoá/khử nitrate và loại bỏ TSS. Nước thải giết mổ được loại bỏ chất rắn, sau đó, được đổ đầy vào bình đựng mở van chỉnh lưu lượng để nước thải chảy vào bể phản ứng giá thể cố định. Bể phản ứng giá thể cố định lưu nước trong vòng 8 tiếng và đưa nước ra công đoạn xử lý sau. Vì mô hình bể đơn giản và kinh phí thấp nên chưa thể rửa ngược một cách tự động. Sau một khoảng thời gian chạy hệ thống cần rửa bể vì các cặn đọng lại dưới bể gây ngẽn đầu ra và có thể khiến nước thải sau xử lý có hàm lượng TSS cao. Màng biofim có hiện tượng tróc màng nên cần có hệ thống xử lý phía sau hoặc bể lắng để đảm bảo nước đầu ra. 
Theo dõi mô hình: Quá trình thí nghiệm chia là hai giai đoạn: giai đoạn thích nghi và giai đoạn khảo sát thông số chỉ tiêu chất lượng nước thải.

Giai đoạn thích nghi: quan sát hạt vật liệu, các vi sinh vật dính bám và thích nghi tạo lớp màng sinh học (biofilm) bao phủ hạt vật liệu.

Giai đoạn khảo sát thông số chỉ tiêu chất lượng nước thải: BOD, TSS, amoni và đánh giá hiệu suất xử lý.

\section{Kết quả và thảo luận}

\subsection{Giai đoạn thích nghi và hình thành màng biofilm}

Trong thời gian khởi động mô hình, nước máy được cho chạy qua bể thử nghiệm một tuần. Chủng vi sinh của chế phẩm vi sinh EM PRO-1 được bổ sung với tỷ lệ 1:19 tương ứng1 lít chế phẩm, 19 lít nước. Trong thời gian chạy thử nghiệm 1 tuần với nước trắng, bổ sung $50 \mathrm{ml}$ chế phẩm vi sinh tương đương với $1 \mathrm{~L}$ nước, rải đều trên bề mặt vật liệu, bổ sung nhiều lần. Bề mặt vật liệu chưa có sự thay đổi (Hình1). Sau khoảng thời gian 3 tuần từ lúc chạy nước thải, bắt đầu hình thành màng biofilm (Hình 2), thời gian hình thành màng tương đối nhanh. Màng biofilm mỏng, có thể nhìn bằng mắt thường và nhận biết khi chạm vào. Hiện tượng "tróc màng" cũng xảy ra trong bể biofilter, nước thải đầu ra thường xuyên có những mảng nhờn đục. Nguyên nhân là do các chất hữu cơ trước hết bị hủy bởi vi sinh vật hiếu khí. Tiếp tục thấm sau vào màng, nước thải hết oxi hòa tan và bị phân hủy tiếp tục bởi vi sinh vật kị khí. Khi các chất hữu cơ trong nước thải cạn kiệt, vi sinh vật ở màng sinh học sẽ chuyển sang hô hấp nội bào và khả năng kết dính cũng giảm, dần dần bị cuốn theo dòng nước đầu ra. Vì vậy cần bể lắng thứ cấp hoặc công đoạn xử lý tiếp theo để đảm bảo TSS cho nguồn nước thải đầu ra. Sau 2 tháng chạy nước thải các lỗ rỗng bề mặt vật bị lấp đầy chất rắn lơ lửng có mặt trong nước thải (Hình 3), làm hạn chế việc hoạt động của vi sinh vật, cần tiến hành rửa ngược để tái sinh vật liệu.

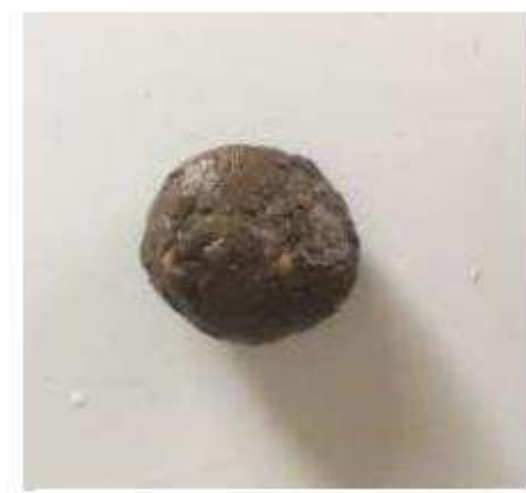

Hình 3.1 (a): 1 tuần

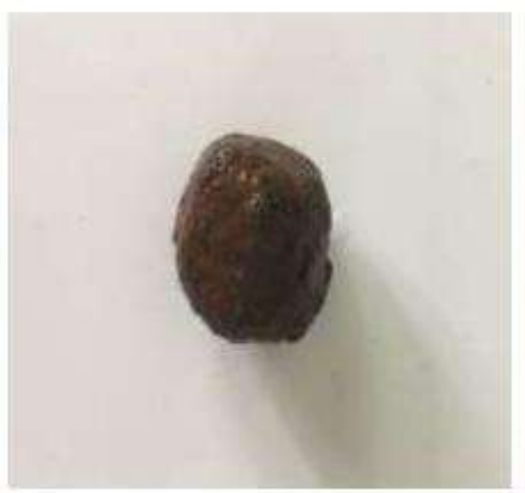

Hình 3(b): 3 tuần

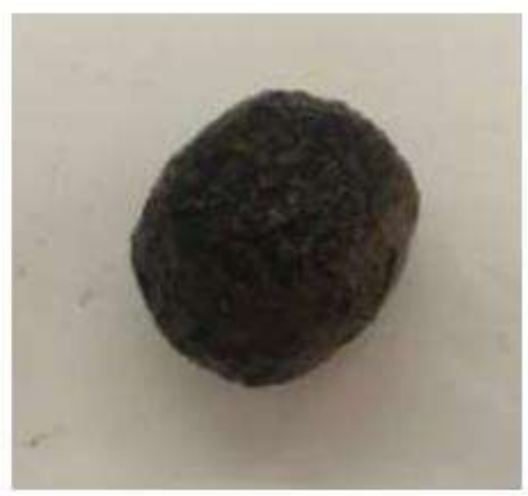

Hình 3.1 (c): 2 tháng

Hình 3. Bề mặt vật liệu dính bám sau khoảng thời gian nhất định nước thải

Tiến hành dùng khoảng 10 viên vật liệu dính bám lắc nhẹ với $10 \mathrm{ml}$ nước trắng, để chủ động gây hiện tượng tróc màng. Lấy một ít của lớp màng tróc mỏng quan sát dưới kính hiển vi 
bước đầu quan sát được vi sinh vật có mặt trong màng biofilm (Hình 4). Quan sát tương tự cũng được trình bày bởi Costerton, Lewandowski, Caldwell, Korber, và Lappin-Scott, (1995).
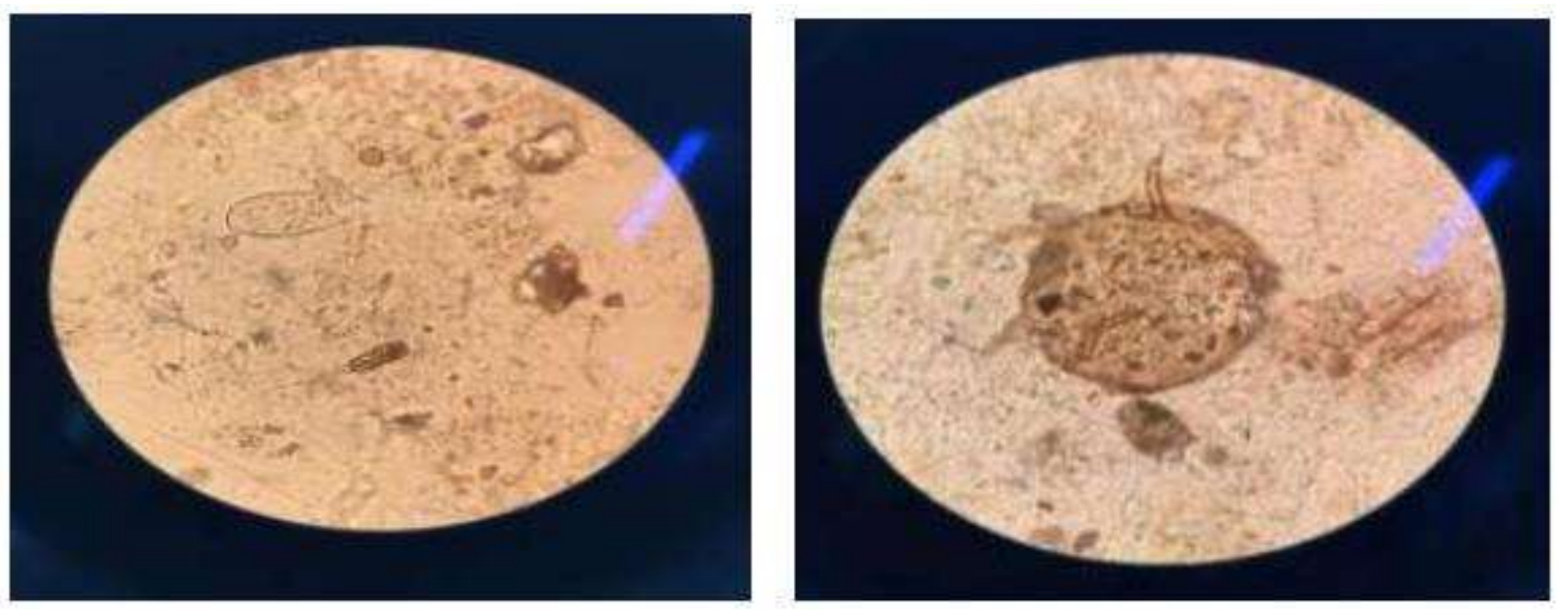

Hình 4. Vi sinh vật quan sát dưới kính hiển vi ở giai đoạn thích nghi

\subsection{Hiệu quả xủ̉ lý BOD, TSS, Amoni, độ đục}

\subsubsection{Hiệu quả xử lý $B O D$}

Sau một tháng chạy ổn định hệ thống, hiệu xuất xử lý ghi nhận tăng dần cho thấy bể biofilter đã bắt đầu xử lý được BOD. Và đến cuối tháng 12 , hiệu xuất cao và ổn định $88,19 \%$. Hệ vi sinh vật trong màng biofilm đã hoạt động tốt và $\mathrm{BOD}$ nước thải đã bị vi sinh vật thủy phân dùng làm chất dinh dưỡng giúp làm giảm BOD ở đầu ra nước thải. Tuy nhiên, $\mathrm{BOD}$ của nước thải đầu ra vẫn còn rất cao không đạt QCVN40:2011/BTNMT, chưa đủ tiêu chuẩn để xả thải ra môi trường, cần có hệ thống xử lý tiếp theo trước khi đưa vào nguồn tiếp nhận. Một phần nguyên do là nồng độ ô nhiễm của nước thải giết mổ khá cao và cũng do quy mô của nghiên cứu nhỏ chưa đủ đáp ứng việc xử lý triệt bể BOD.

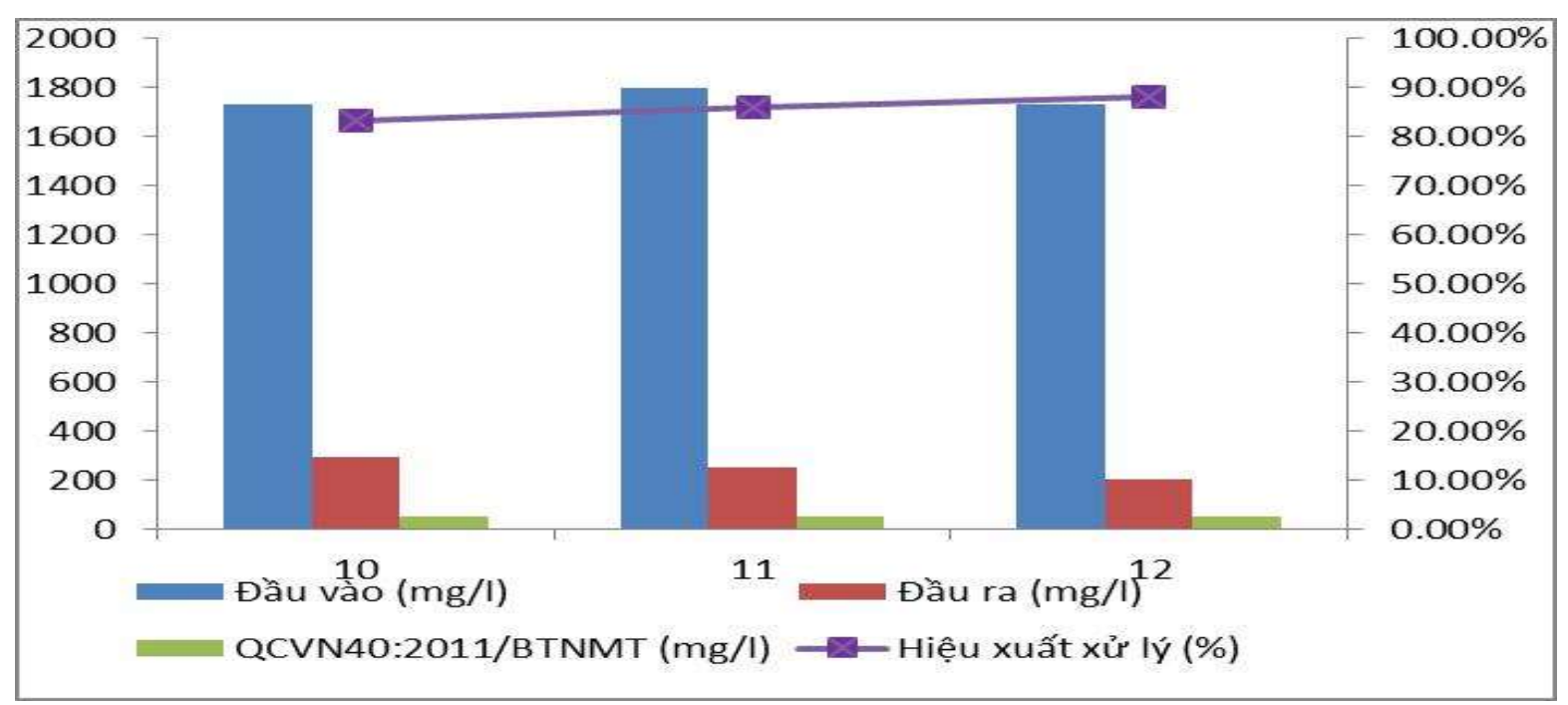

Hình 5. Nồng độ và hiệu xuất BOD trung bình qua 3 tháng nghiên cứu 


\subsubsection{Hiệu quả xủ lý TSS}

Hiệu xuất xử lý TSS tăng dần và đạt $76,18 \%$ trong tháng 12 . Hiệu quả xử lý tổng rắn lơ lửng cao có thể giải thích bởi lỗ rỗng giữa các vật liệu nhỏ, góp phần giữ lại TSS. Bên cạnh đó, vi sinh trong bể phân hủy rắn hữu cơ, một thành phần của TSS, làm giảm TSS đầu ra. Sau 1 đến 2 tháng hoạt động bể, bể được xả cặn một lần để đảm bảo không làm nghẽn đầu ra và giữ TSS được ổn định, do bể được thiết kế đơn giản nên quá trình rửa bể sẽ tiến hành thủ công. Mặc dù hiệu quả xử lý TSS là cao, tuy nhiên TSS dòng ra không đạt QCVN40/2011-BTNMT, vì một phần màng biofilm xảy ra hiện tượng bong tróc, đây là quá trình sinh hóa tự nhiên của màng sinh học. Qua nghiên cứu này, kết quả cho thấy để xử lý nước thải giết mổ một cách hiệu quả thì bể phản ứng sinh học biofilter chỉ nên là công trình tiền xử lý nhằm làm giảm TSS và BOD. Nước thải giết mổ, sau Biofilter, vẫn phải tiếp tục được xử lý bằng các công đoạn sau để xử lý đạt QCVN. Uu điểm của bể Biolfilter có thể thấy là làm giảm tải lượng ô nhiê̂m cho các công đoạn xử lý tiếp theo.

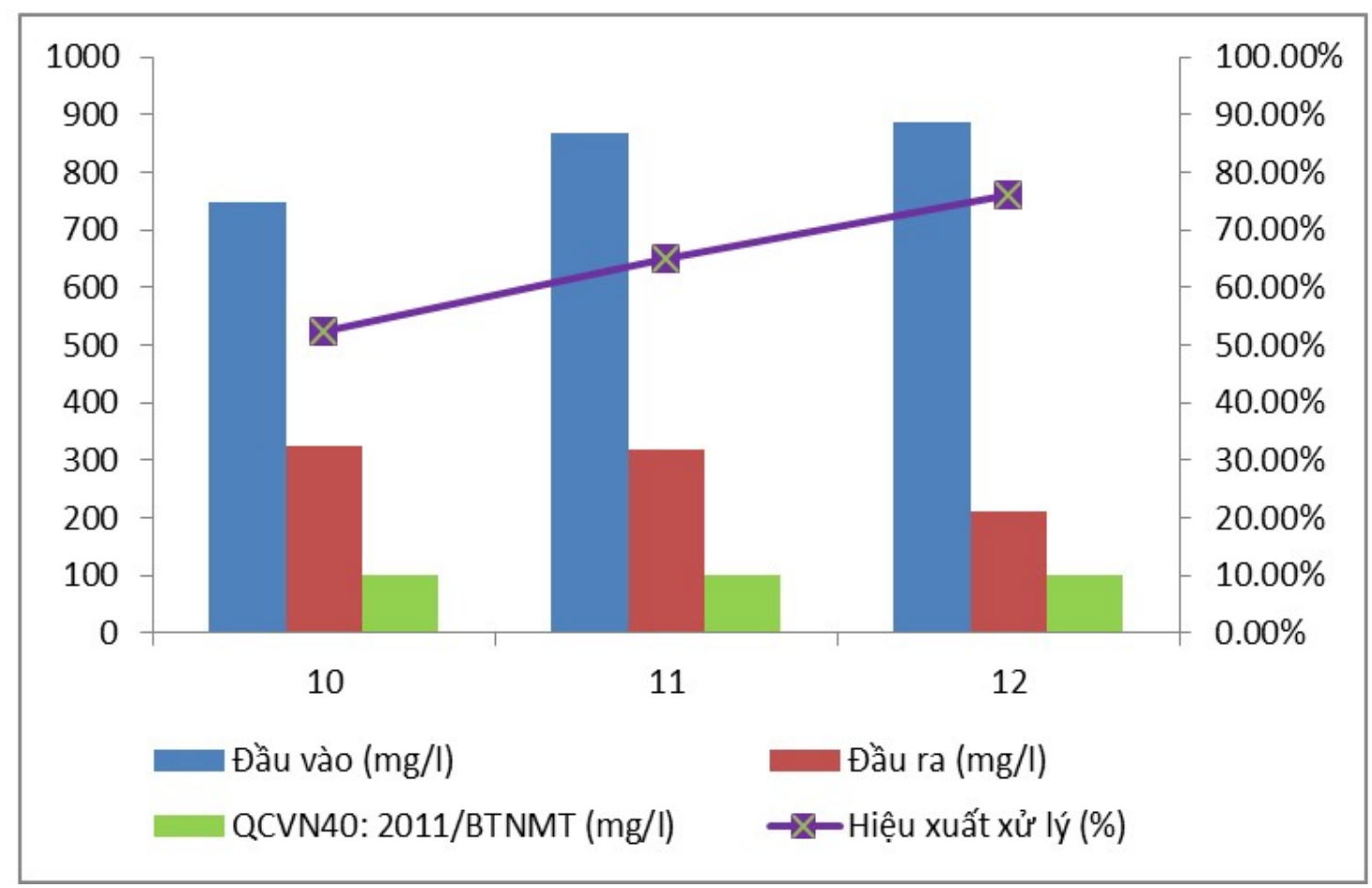

Hình 6. Nồng độ và hiệu xuất TSS trung bình qua 3 tháng nghiên cứu

\subsubsection{Hiệu quả xủ lý Amoni}

Bể phản ứng phản ứng sinh học giá thể cố định tạo môi trường hiếu khí để vi khuẩn Nitrosomonas và vi khuẩn Nitrobacter hoạt động tốt đồng thời xử lý amoni. Mặc dù hiệu xuất xử tăng dần và đạt mức cao $66,07 \%$ vào tháng 12 . Tuy nhiên việc xử lý amoni phụ thuộc vào quá trình hình thành cũng như hiện tượng tróc màng của màng sinh học. Điều này làm việc thông số amoni trong nước thải đầu ra không ổn định và có nhiều lần ghi nhận không đạt QCVN. Việc này càng góp phần làm rõ nhận định bể phản ứng giá thể cố định là giai đoạn tiền xử lý cần có công đoạn xử lý tiếp theo để đảm bảo việc xả thải đúng qui định. 
Riêng nồng độ $\mathrm{NO}_{3}^{-}$không có quy định trong quy chuẩn xả thải QCVN 40:2011/BTNMT nên nồng độ chỉ tiêu này dùng để đánh giá sự chuyển hóa đạm hữu cơ trong nước thải. $\mathrm{NH}^{+}$của nước thải đầu ra thấp hơn nhiều so với đầu vào, trong khi đó $\mathrm{NO}^{-}$tăng chứng tỏ đạm hữu cơ đã được chuyển hóa thành đạm a-môn và sau đó bị oxy hóa thành đạm nitrat, tuy nhiên lượng đạm nitrat tăng lên không tương xứng với mức giảm của đạm hữu cơ và a-môn, chứng tỏ trong bể còn có quá trình khử nitrat diễn ra, mặc dù không đáng kể. Trong nghiên cứu này kỳ vọng sẽ xảy ra quá trình khử hoàn toàn nitrit, sẽ tách oxy của nitrat và nitrit để oxy hóa các chất hữu cơ. $\mathrm{N}_{2}$ được tạo thành trong quá trình sẽ bay hơi và tách khỏi nước từ đó ta xử lý được $\mathrm{NO}_{3}{ }^{-}$(Park \& Yoo, 2009). Tuy nhiên trong nghiên cứu này chưa đạt được điều đó, dòng thải chảy cung cấp nitrat và sự chuyển hóa của amoni làm các thông số tăng qua từng lần đo thu kết quả, khiến giá trị thu nhận nitrat khá cao. Nguyên nhân có thể do thời gian nghiên cứu giới hạn, chưa đủ điều kiện thuận lợi vi khuẩn khử nitrit và nitrat (Denitrificans) hình thành với môi trường kị khí hoặc thiếu khí hình thành để xử lý nitrat. Vì thế không thể phủ nhận đến thời điểm này kết qủa cho thấy nghiên cứu chưa đáp ứng được điều này.

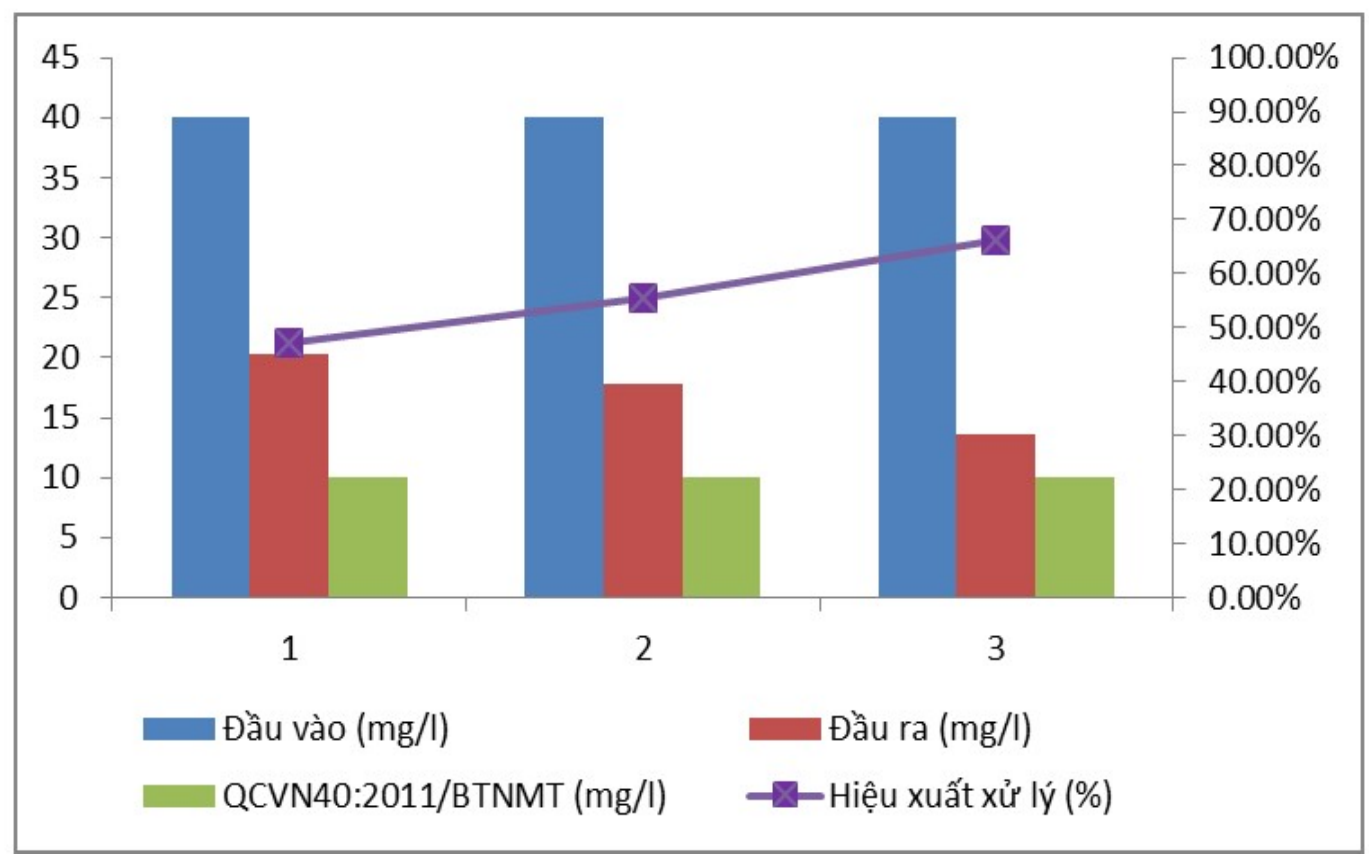

Hình 7. Nồng độ và hiệu xuất Amoni trung bình qua 3 tháng nghiên cứu

\subsubsection{Hiệu quả xủ lý Độ đục}

Bể Biofilter giải quyết rất tốt độ đục, biểu hiện ở việc hiệu xuất xử lý trung bình luôn đạt khoảng $95 \%$. Hiện nay, việc đo độ đục thường ở phần cuối của quá trình xử lý nước thải cần thiết để xác minh rằng các giá trị nằm trong tiêu chuẩn quy định. Độ đục của nước là một đặc tính quang học tạo ra ánh sáng được phân tán và hấp thụ, chứ không phải là truyền đi. Sự tán xạ của ánh sáng đi qua một chất lỏng chủ yếu được gây ra bởi các chất rắn lơ lửng có trong đó. Việc bể phản ứng giá thể cố định xử lý tốt chất lắng lơ lửng cũng chính là giảm độ đục trong nước thải giết mổ. 


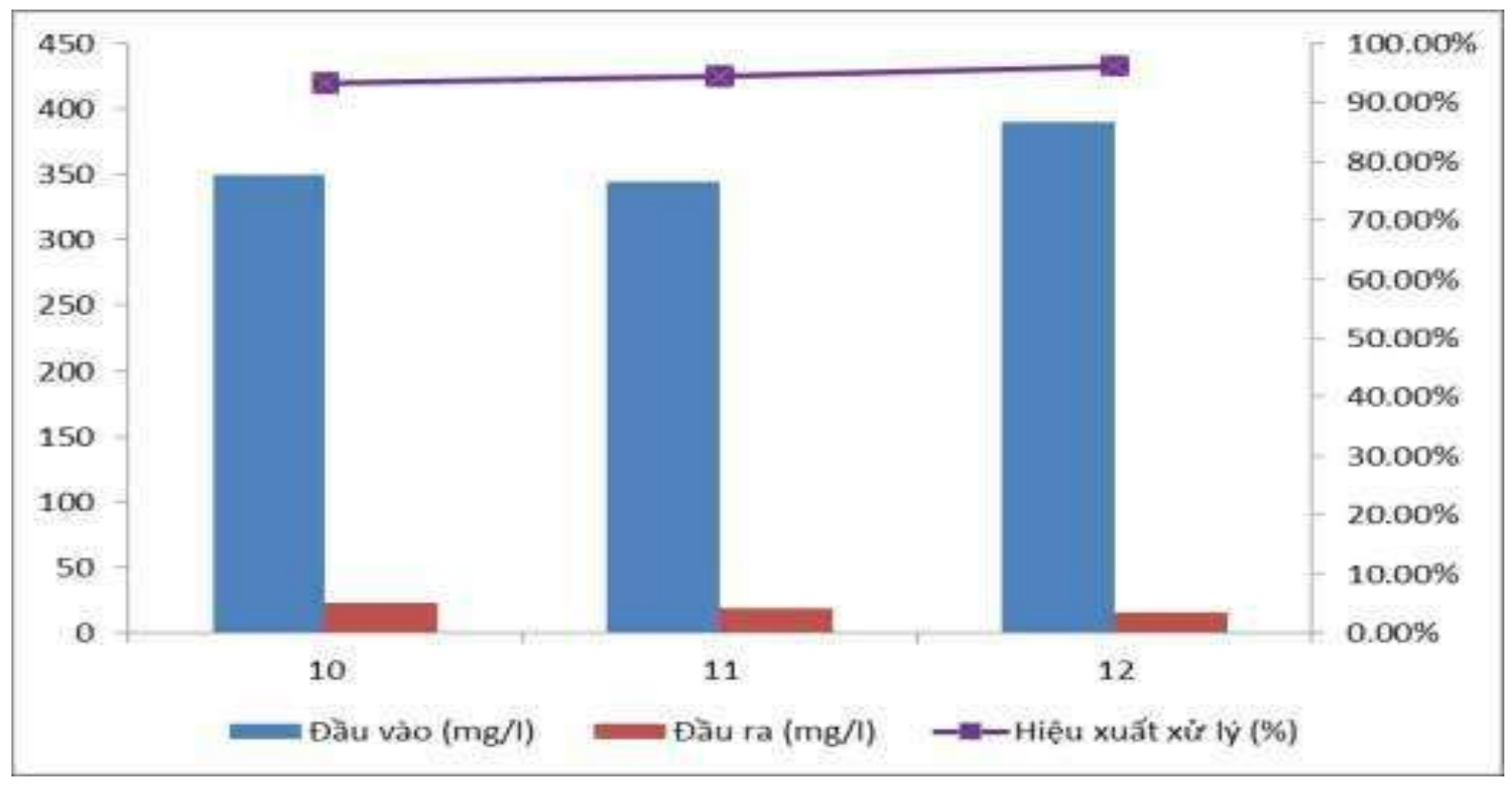

Hình 8. Nồng độ và hiệu xuất Độ đục trung bình qua 3 tháng nghiên cứu

\section{Bảng 3}

Hiệu quả xử lý BOD, TSS, Amoni, Độ đục qua ba tháng chạy hệ thống

\begin{tabular}{|c|c|c|c|}
\hline \multirow{2}{*}{ Chỉ tiêu } & \multicolumn{3}{|c|}{ Trung bình hiệu xuất } \\
\cline { 2 - 4 } & Tháng 10 & Tháng 11 & Tháng 12 \\
\hline BOD & $83.18 \%$ & $86.11 \%$ & $88.19 \%$ \\
\hline TSS & $52.46 \%$ & $64.93 \%$ & $76.18 \%$ \\
\hline Amoni & $47.32 \%$ & $55.36 \%$ & $66.07 \%$ \\
\hline Độ đục & $93.23 \%$ & $94.36 \%$ & $96.11 \%$ \\
\hline
\end{tabular}

Nguồn: Kết quả phân tích dữ liệu của nhóm nghiên cứu

Qua Bảng 3: Cho thấy hiệu xuất xử lý trung bình qua 3 tháng 10,11, 12 của các chỉ tiêu BOD, TSS, Amoni, Độ đục.

\section{Kết luận}

Trong nghiên cứu này, bể phản ứng sinh học giá thể cố định được sử dụng là một phương pháp để tiền xử lý nước thải từ việc giết mổ gia súc. Đây là nguồn nước thải có nồng độ ô nhiễm chất hữu cơ và dinh dưỡng (nitơ và photpho) cao. Nghiên cứu này gồm 2 phần chính: (1) khảo sát thời gian thích nghi và hình thành màng biofim; (2) khảo sát hiệu quả xử lý thông qua các chỉ tiêu chất lượng nước: BOD, TSS, amoni, độ đục.

Trên cơ sở kết quả nghiên cứu đạt được rút ra các kết luận như sau:

- Sau thời gian chạy hệ thống với nước thải giết mổ 3 tuần màng sinh học (biofim) hình thành và có thể xử lý nước thải giết mố;

- Có thể sử dụng các vật liệu phổ biến và giá thành rẻ như đất nung để làm vật liệu bám dính cho bể sinh học xử lý nước thải;

- Trong giai đoạn hình thành màng biofim, có sự xuất hiện vi sinh vật; 
- Kết quả hiệu xuất tốt nhất đạt được qua nghiên cứu là: TSS 78,93\%, BOD 88,77\%, $\mathrm{N}-\mathrm{NH}^{+} 487,50 \%$ và độ đục 96,61\%;

- Mặc dù hiệu xuất xử lý BOD, TSS, amoni khá cao nhưng nước thải sau Biolfilter vẫn chưa đạt QCVN để có thể đưa ra môi trường. Nước thải sau Biofilter cần tiếp tục được xử lý bằng các công nghệ phù hợp để có thể đạt QCVN.

\section{Tài liệu tham khảo}

Choi, E., \& Eum, Y. (2002). Strategy for nitrogen removal from piggery waste. Water Science and Technology, 46(6/7), 347-354.

Costerton, J. W., Lewandowski, Z., Caldwell, D. E., Korber, D. R., \& Lappin-Scott, H. M. (1995). Microbial biofilms. Annual Review of Microbiology, 49, 177-745.

Grady, C. P. L., Jr., Glen, T. D., \& Henry, C. L. (1999). Biological wastewater treatment: Second edition. New York, NY: Marcel Dekker, Inc.

Le, C. N. P., Le, T. C. H., \& Nguyen, H. T. L. (2012). Xử lý ammonium trong nước thải giết mổ bằng việc kết hợp quá trình nitrit hóa một phần/anammox [Ammonium treatment in slaughter wastewater by combining partial nitrification / anammox]. Tap chi Sinh hoc, 34(3SE), 105-110.

Luong, D. P. (2007). Công nghệxử lý nuớc thải bằng biện pháp sinh học [Wastewater treatment technology by biological methods]. Ho Chi Minh, Vietnam: NXB Giáo dục Việt Nam.

Metcalf, \& Eddy (2016). Wastewater engineering - Treatment and reuse (4th ed). New York: NY: McGraw-Hill.

Nguyen, V. P. (2010). Giáo trình Xử lý nước thải sinh hoạt và công nghiệp bằng phuoong pháp sinh hoat [Curriculum for domestic and industrial wastewater treatment by living method]. Hanoi, Vietnam: NXB Xây dựng.

Nguyen, V. T. (1998). Bước đầu nghiên cứu sư dụng chitosan vào quá trình keo tu để xủ lý nuớc thải [Initial research on using chitosan in the flocculation process for wastewater treatment] (Bachelor's thesis). Hue University of Sciences, Hue, Vietnam.

Park, J. Y., \& Yoo, Y. J. (2009). Biological nitrate removal in industrial wastewater treatment. Microbiology and Biotechnology, 82(3), 415-429.

Thông tấn xã Việt Nam. (2017). Bến Tre sẽ không còn điểm giết mổ gia súc, gia cầm nhỏ lẻ vào năm 2020 [Ben Tre will no longer have small cattle and poultry slaughterhouses by 2020]. Retrieved January 10, 2019, from Cổng thông tin điện tử Bộ Nông Nghiệp và Phát Triển Nông Thôn website: https://www.mard.gov.vn/Pages/ben-tre-se-khong-con-diemgiet-mo-gia-suc-gia-cam-nho-le-vao-nam-2020-34005.aspx

Trinh, X. L. (2009). Tính toán thiết kế các công trình xủ lý nuớc thải [Calculation and design of wastewater treatment facilities]. Hanoi, Vietnam: NXB Xây dựng. 